УДК 323.2

АНИСИМОВ Иван Викторович - аспирант кафедры политологии и социологии Бурятского государственного университета им. Доржи Банзарова (670000, Россия, Республика Бурятия, г. УланУдэ, ул. Смолина, 24a; ivan_anisimov07@mail.ru)

НОЛЕВ Евгений Владимирович - кандидат исторических наук, научный сотрудник отдела истории и культуры Центральной Азии Института монголоведения, буддологии и тибетологии СО РАН (670047, Россия, Республика Бурятия, г. Улан-Удэ, ул. Сахьяновой, 6; поlеv@inbox.ru)

\title{
ОНФ В РЕСПУБЛИКЕ БУРЯТИЯ: УЧАСТИЕ ГРАЖДАНСКОГО ОБЩЕСТВА В РЕАЛИЗАЦИИ ВАЖНЕЙШИХ НАПРАВЛЕНИЙ ГОСУДАРСТВЕННОЙ ПОЛИТИКИ
}

Аннотация. Статья посвящена исследованию деятельности регионального отделения ОНФ в Республике Бурятия по формированию механизмов вовлечения граждан и расширения их участия в реализации государственной политики. Становление и развитие направлений работы регионального отделения рассматривается в контексте истории Общероссийского общественного движения «Народный фронт «За Россию». Особое внимание уделяется вопросам трансформации структуры и задач движения в контексте указа Президента РФ «О национальных целях и стратегических задачах развития Российской Федерации на период до 2024 года».

Ключевые слова: Общероссийский народный фронт, Республика Бурятия, национальные цели, гражданское общество, участие граждан

6 мая 2011 г. В.В. Путин, будучи премьер-министром Российской Федерации, выступил на пленарном заседании межрегиональной конференции региональных отделений партии «Единая Россия» в Южном федеральном округе с предложением о создании нового политического объединения в преддверии выборов в Государственную думу - Общероссийского народного фронта, призванного сплотить близкие по духу политические силы и обеспечить «приток новых лиц, свежих идей и предложений в “Единую Россию”»1.

Выборы президента 2012 г. сыграли значительную конституирующую роль в формировании структуры и задач нового общественного движения. 4 марта 2012 г. на встрече с активистами ОНФ В.В. Путин обозначил цели своей инициативы и задачи нового движения: «общество нуждается в контроле со стороны неравнодушных к судьбе страны граждан и общественных формирований над исполнением указов и поручений главы государства, а также в активной помощи граждан в борьбе с коррупцией, захватившей страну» [Кузина, Орешкина 2018: 139]. Доверенные лица В.В. Путина, назначенные во время предвыборной кампании, как правило, впоследствии становились членами региональных штабов ОНФ. В Бурятии доверенными лицами стали первый президент республики, ведущий научный сотрудник отдела региональных экономических исследований Бурятского научного центра СО РАН доктор экономических наук Л.В. Потапов, заведующий кафедрой политологии и социологии Бурятского государственного университета, генеральный директор ИД «Буряад Унэн» доктор социологических наук Э.Д. Дагбаев и декан агрономического факультета Бурятской государственной сельскохозяйственной академии доктор сельскохозяйственных наук А.Г. Кушнарев.

На заре создания этот уникальный для нашего государства общественно-поли-

\footnotetext{
${ }^{1}$ Путин: «Народный фронт» создается для притока в «Единую Россию» новых идей и лиц. - Газета. Ru. 07.05.2011. Доступ: https://www.gazeta.ru/news/lenta/2011/05/07/n_1828329.shtml (проверено 18.10.2019).
} 
тический проект получил различные оценки на федеральном и региональном уровнях в силу неопределенности функциональных задач, полномочий и структуры, что формировало основания для расширенных трактовок при описании возможных перспектив. Одни исследователи ассоциировали создания ОНФ с появлением нового феномена в российском политическом поле - «народной власти», призванного расширить и усовершенствовать механизмы интеграции гражданских инициатив и отдельных граждан в политическую жизнь страны, в процесс принятия политических решений за счет «более активного вовлечения гражданских масс в общественно-политическую деятельность, которое не представляется возможным в рамках партийной структуры с фиксированным членством» [Джиоева 2012: 7]. Также в общественно-политическом дискурсе присутствовали полярные мнения - от сугубо утилитарного назначения ОНФ в качестве инструмента предвыборных кампаний до создания Народного фронта в качестве новой партии власти.

На учредительном съезде, прошедшем в Москве с 11 по 12 июня 2013 г., было закреплено официальное название организации - «Общероссийское общественное движение «Народный фронт «За Россию». В качестве целей движения, закрепленных в уставе, были обозначены «направления деятельности, ориентированные на содействие единению и взаимному доверию, сотрудничеству и гражданской солидарности во имя исторического успеха России, ее свободы, процветания, благополучия и безопасности за счет развития гражданского общества, поддержки и обеспечения прямого и постоянного диалога между обществом и властью, вовлечения граждан в постоянную совместную работу по определению приоритетов и решению важнейших вопросов развития страны» 1 . Съезд избрал лидером ОНФ действующего президента РФ В.В. Путина и закрепил надпартийный характер движения. По инерции началось создание региональных отделений в субъектах РФ.

Координатором создания ОНФ в Бурятии стал председатель президиума Бурятского научного центра СО РАН академик РАН Б.В. Базаров. Учредительное собрание регионального отделения ОНФ состоялось 22 октября 2013 г. В ходе собрания был сформирован региональный штаб движения, избраны сопредседатели и ревизионная комиссия. В состав учредителей регионального отделения ОНФ в Республике Бурятия вошли руководители общественных организаций, представители учреждений социальной сферы, производственных предприятий и бизнеса, выдающиеся деятели науки и культуры, а также видные политические деятели [Анисимов, Нолев 2018: 68]. В разные годы деятельности регионального отделения его сопредседателями становились проректор по учебной работе ВСГУТУ доктор технических наук П.К. Хардаев; председатель Ассоциации национально-культурных центров «Дом дружбы» кандидат педагогических наук С.Р. Баталова; директор по финансам и экономике АО «Вертолеты России» С.С. Желтиков; главный врач городской поликлиники № 2 В.В. Колмакова; депутат Государственной думы РФ Н.Р. Будуев; доцент ВСГУТУ кандидат экономических наук Н.Ю. Сандакова; координатор проекта «Дорожная инспекция ОНФ / Карта убитых дорог» в Республике Бурятия М.С. Кириенко. Исполком регионального отделения с 2014 по 2017 г. возглавлял депутат Народного хурала Республики Бурятия И.В. Марковец; с 2017 г. по настоящее время - Ю.В. Ким.

Приоритетами деятельности движения стали контроль за исполнением законов, президентских инициатив и иных ключевых государственных решений и программ. ОНФ осуществлял общественный мониторинг исполнения

\footnotetext{
1 Устав Общероссийского общественного движения «Народный фронт «За Россию». 2013. М. С. 2, 3.
} 
указов Президента, принятых 5 мая 2012 г. «Майские указы» стали основой для формирования структуры организации на федеральном и региональном уровнях в виде следующих рабочих групп: «Общество и власть: прямой диалог», «Социальная справедливость», «Качество повседневной жизни», «Образование и культура как основы национальной идентичности», «Честная и эффективная экономика». При этом следует отметить, что на начальном этапе своей деятельности к сфере контроля ОНФ за исполнением указов Президента были отнесены только 7 из 11. Вне сферы прямого гражданского контроля со стороны Народного фронта остались вопросы долгосрочной государственной экономической политики (указ № 596), обеспечения межнационального согласия (указ № 602), развития вооруженных сил и модернизации военно-промышленного комплекса (указ № 603), совершенствования военной службы в Российской Федерации (указ № 604), а также вопросы реализации внешнеполитического курса (указ № 605).

Наряду с деятельностью рабочих групп в Республике Бурятия были реализованы следующие проекты ОНФ: «Карта жизни», «Народная оценка качества», «За честные закупки», «Равные возможности - детям», «Профстажировки», «Зеленый щит», патриотические проекты. В региональном отделении была организована работа Центра мониторинга благоустройства городской среды. В рамках расширения федеральной повестки в деятельности ОНФ происходило формирование новых направлений и механизмов работы регионального отделения. В 2015 г. был создан региональный центр мониторинга по проблемам экологии и защиты леса, что оказалось особенно востребованным для Бурятии в условиях роста числа пожаров в засушливые годы. Благодаря развитию интерактивных инструментов общественного контроля и активному их внедрению в практику ОНФ посредством интернет-ресурсов были расширены возможности участия граждан в улучшении качества жизни. В 2017 г. в рамках созданного проекта ОНФ «Дорожная инспекция ОНФ / Карта убитых дорог» граждане получили возможность участия в формировании дорожной политики в регионах и улучшении качества дорог посредством размещения информации о дефектах дорожного покрытия на сайте проекта dorogi-onf.ru, что стало основанием для запуска процедуры ремонта отмеченных дорог. По состоянию на 2019 г. пользователи сайта отметили 139 плохих дорог в регионе, 11 из которых отремонтированы, а на 27 произведен ямочный ремонт. Аналогичный механизм гражданского участия был положен в основу проекта ОНФ «Генеральная уборка», направленного на повышение эффективности общественного контроля со стороны граждан за санитарным состоянием своего региона, посредством размещения информации на открытом сетевом ресурсе «Интерактивная карта свалок». Из 98 несанкционированных свалок, отмеченных жителями республики на карте, 28 были ликвидированы, а вопрос об остальных находится на стадии рассмотрения.

Вместе с тем деятельность регионального отделения ОНФ не ограничивается федеральной повесткой, а актуализирует также ключевые вопросы развития Республики Бурятия. Одним из важнейших направлений работы ОНФ в регионе стал вопрос об охране оз. Байкал и социально-экономическом развитии байкальской природной территории, предполагающий разработку механизмов развития Республики Бурятия в условиях действия природоохранных ограничений [Анисимов, Нолев 2018: 69]. В июне 2019 г. по инициативе ОНФ состоялось экспертное совещание по обсуждению вопросов, касающихся разработки республиканской концепции национально-культурного брендирования с целью развития туризма. В августе 2019 г. на совещании у главы Республики Бурятия А.С. Цыденова, посвященном проблемам загрязнения атмосферного 
воздуха в г. Улан-Удэ, была рассмотрена инициатива ОНФ по созданию лесопаркового зеленого пояса.

2018 г. стал рубежным для Общероссийского народного фронта. Общественное движение, чья деятельность была сосредоточена на контроле за выполнением большей части «майских указов» 2012 г. и обеспечении возможности исполнения гражданских инициатив в рамках осуществления государственной политики, доказало свою состоятельность и эффективность в решении задачи расширения общественного участия граждан. 12 июля 2018 г. состоялось заседание центрального штаба ОНФ «О предложениях ОНФ в национальные проекты и программы, формируемые Правительством России в соответствии с Указом Президента Российской Федерации от 7 мая 2018 г. № 204 “О национальных целях и стратегических задачах развития Российской Федерации на период до 2024 года"». Было принято решение о преобразовании рабочих групп центрального штаба в тематические площадки ОНФ по 12 направлениям, соответствующим национальным проектам и программам ${ }^{1}$. Среди них такие направления, как демография, здравоохранение, образование, жилье и городская среда, экология, безопасные и качественные автомобильные дороги, производительность труда и поддержка занятости, наука, цифровая экономика, культура, малое и среднее предпринимательство и поддержка индивидуальной предпринимательской инициативы, международная кооперация и экспорт. Новый формат работы регионального отделения ОНФ в Республике Бурятия был утвержден на заседании региональной конференции 5 октября 2018 г. При этом было отмечено, что вместе с работой новых тематических площадок будет продолжена реализация приоритетных проектов ОНФ «Генеральная уборка», «Дорожная инспекция ОНФ / Карта убитых дорог», «Народная оценка качества». Сопредседатель регионального отделения П.К. Хардаев указал, что «главными задачами общественников является не только проведение мониторингов, рейдов и выявление нарушений, но и формирование предложений для эффективной реализации приоритетных направлений в рамках взаимодействия с органами государственной власти» 2 .

На заседании Совета по стратегическому планированию в рамках реализации мониторинга хода выполнения указа Президента РФ «О национальных целях и стратегических задачах развития Российской Федерации на период до 2024 года», состоявшегося 24 октября 2018 г., Общероссийскому народному фронту было предложено обеспечить мониторинг хода выполнения указа Президента РФ, в т.ч. в части влияния на качество жизни граждан изменений, достигнутых в ходе реализации национальных проектов 3 . Существенным отличием от мониторинга «майских указов» 2012 г. стало осуществление участия ОНФ в реализации и контроле за исполнением всех направлений указа Президента РФ.

Выступая на съезде Общероссийского народного фронта 29 ноября 2018 г., В.В. Путин обозначил историческое предназначение ОНФ как контроль со стороны общества за государственными решениями, за их исполнением. Высоко оценив результаты деятельности движения, президент сформулировал ключе-

\footnotetext{
${ }^{1}$ Указ Президента РФ от 07.05.2018 № 204 « национальных целях и стратегических задачах развития Российской Федерации на период до 2024 года». 2018. М. Кремль. 19 с.

2 Активисты Народного фронта в Бурятии обсудили новые форматы работы на региональной конференции ОНФ. - Общероссийский народный фронт. Официальный сайт. 05.10.2018. Доступ: https:// onf.ru/2018/10/05/aktivisty-narodnogo-fronta-v-buryatii-obsudili-novye-formaty-raboty-na-regionalnoy/ (проверено 01.08.2019).

3 Протокол заседания Совета по стратегическому развитию и нацпроектам. - Президент России. Официальный сайт. 02.11.2018. Доступ: http://kremlin.ru/acts/assignments/orders/59037 (проверено 01.08.2019).
} 
вые направления дальнейшей работы. Во-первых, широкий общественный контроль за реализацией государственной политики на всех уровнях. Во-вторых, поддержка государства, включая помощь «тем людям в органах власти, которые работают с душой, ответственно». В-третьих, прямое участие в выработке приоритетов развития, особенно на региональном уровне ${ }^{1}$.

Таким образом, в результате работы регионального отделения ОНФ в Республике Бурятия были созданы условия для участия гражданского общества в контроле, мониторинге и реализации важнейших направлений государственной политики в регионе, и в то же время сформирована площадка для широкого общественного диалога с целью решения актуальных проблем и стратегического развития Республики Бурятия.

Статья подготовлена в рамках государственного задания (проект ХІІ.191.1.2 «Межкультурное взаимодействие, этнические и социально-политическиепроцессыв Центральной Азиџ», номер госрегистрации № АAAA-A17-117021310264-4).

\title{
Список литературы
}

Анисимов И.В., Нолев Е.В. 2018. Общероссийский народный фронт в Республике Бурятия: организация и направления деятельности регионального отделения. - Республике Бурятия - 95 лет: сборник научных статей. Улан-Удэ: Изд-во БНЦ СО РАН. С. 67-69.

Джиоева В.А. 2012. Перспективность Общероссийского народного фронта как инновационной составляющей в области партийного строительства. Современные исследования социальных проблем: электронный научный журнал. № 4(12). 11 с. Доступ: https://cyberleninka.ru/article/v/perspektivnostobscherossiyskogo-narodnogo-fronta-kak-innovatsionnoy-sostavlyayuschey-voblasti-partiynogo-stroitelstva (проверено 18.10.2019).

Кузина С.И., Орешкина Ж.Ю. 2018. Политическое проектирование в процессах модернизации российской политической системы. - Государственное и муниципальное управление. Ученые записки. № 2. С. 136-142.

ANISIMOV Ivan Viktorovich, postgraduate student at the Chair of Political Science and Sociology, Banzarov Buryat State University(24a Smolina St, Ulan-Ude, Republic of Buryatia, Russia, 670000; ivan_anisimov07@mail.ru)

NOLEV Evgeniy Vladimirovich, Cand. Sci. (Hist.), Researcher of the Institute for Mongolian, Buddhist and Tibetan Studies, Siberian Branch of Russian Academy of Sciences (6 Sah'janovoj St, Ulan-Ude, Republic of Buryatia, Russia, 670047;nolev@inbox.ru)

\section{ALL-RUSSIAN PEOPLE'S FRONT IN THE REPUBLIC OF BURYATIA: CIVIL SOCIETY PARTICIPATION IN THE REALIZATION OF THE STATE POLICY}

\begin{abstract}
The article deals with the history of the formation, organization and directions of activity of the regional office of AllRussian People's Front in the Republic of Buryatia. The authors analyze the influence of the regional office of this movement on the formation of mechanisms for involving citizens and expanding their participation in the realization of the state policy. The formation and development of the work directions of the regional office is considered in the context of history of AllRussian People's Front. The authors pay special attention to the issues of transforming the structure and tasks of the social
\end{abstract}

\footnotetext{
${ }^{1}$ Съезд Общероссийского народного фронта. - Президент России. Официальный сайт. 29.11.2018. Доступ: http://kremlin.ru/events/president/news/59260 (проверено 01.08.2019).
} 
movement in the context of the Decree of the President of the Russian Federation "On National Goals and Strategic Tasks of the Development of the Russian Federation for the Period until 2024».

Keywords: All-Russian People's Front, Republic of Buryatia, national goals, civil society, citizen participation

\title{
УДК 314.15
}

АДИЕВ Асланбек Залимханович - кандидат политических наук, ученый секретарь Регионального центра этнополитических исследований Дагестанского федерального исследовательского иентра РАН(367000, Россия, Республика Дагестан, г. Махачкала, ул. Магомета Гаджиева, 45; khalid_84@ mail.ru)

БИЙЖАНОВА Элиза Камчыбековна - научный сотрудник Центра региональной социологии и конфликтологии Института социологии Федерального научно-исследовательского социологического центра РАН (117218, Россия, г. Москва, ул. Кржижановского, 24/35, корп. 5; biyzhanova@isras.ru)

\section{МИГРАЦИОННЫЕ ПРОЦЕССЫ И ДЕМОГРАФИЧЕСКИЙ РЕСУРС ДАГЕСТАНА: ДИНАМИКА И МУНИЦИПАЛЬНЫЕ ОСОБЕННОСТИ}

\begin{abstract}
Аннотация. Республика Дагестан воспринимается экспертным сообществом как один из демографически благополучных регионов Российской Федерации с устойчиво высокими темпами естественного прироста населения. В статье на основе анализа статистических данных, а также материалов социологических исследований рассматривается динамика демографических и миграционных процессов в Республике Дагестан, ведущих к стабилизации численности населения региона за счет уменьшения рождаемости и усиления миграционного оттока. Сопоставление тенденций по показателям рождаемости, смертности и миграции за последние десять лет (2010-2019 гг.) позволяет прогнозировать замедление темпов роста населения республики, что подтверждается динамикой численности постоянного населения в отдельных муниципальных районах Дагестана.
\end{abstract}

Ключевые слова: Дагестан, демографическая ситуация, миграция, прогноз

Постановка проблемы. В Российской Федерации устойчиво идет процесс вымирания села. С карты страны за постсоветский период исчезли сотни сельских некогда населенных пунктов. Это следствие общемирового тренда - урбанизации, стимулирующей ускоренный рост городских агломераций за счет человеческих ресурсов сельских территорий и иммиграции. В большинстве концептуальных документов, принятых за последние годы в России в сфере социальной политики, отмечается проблема концентрации населения страны в нескольких крупных городских агломерациях; оттока населения из сельских территорий, особенно из периферийных и стратегически значимых регионов страны. На фоне этих демографических и миграционных тенденций за северокавказскими республиками закрепился образ демографически благополучных и трудоизбыточных субъектов, где отмечается естественный прирост населения и миграционная убыль в направлении других регионов страны. Наиболее трудоизбыточным из всех северокавказских республик представляется Дагестан, откуда миграционная убыль населения составляет около 12 тыс. чел. ежегодно (в остальных республиках этого макрорегиона ежегодная миграционная убыль фиксируется в пределах 2-4 тыс. чел.). При этом население республики продолжает расти. Но останется ли Дагестан в демографическом плане и дальше одним из наиболее благополучных регионов страны? Каковы территориальные 